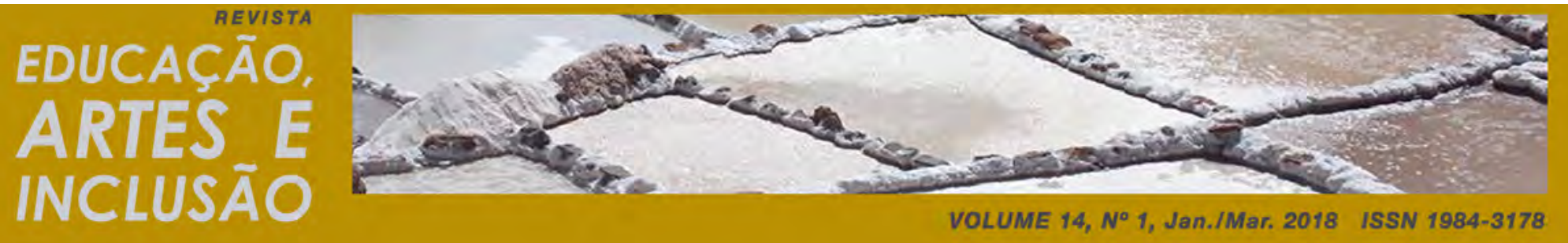

\title{
EDUCAÇÃO PELA ARTE - EXPERIÊNCIAS TEATRAIS NA EDUCAÇÃO DO CAMPO (2010-2013)
}

\section{EDUCATION BY ART - THEATRICAL EXPERIENCES IN FIELD EDUCATION (2010-2013)}

DOI: http://dx.doi.org/10.5965/1984317814012018156

Monique Lima de Oliveira - Universidade Estadual de Campinas

\begin{abstract}
RESUMO
Este texto é um breve relato de experiência e provém da pesquisa de mestrado $O$ teatro na formação de educadores - Experimentos com a Licenciatura em Educação do Campo da UFRRJ, defendida em 2013 pelo Programa de Pós-graduação em Educação, Contextos Contemporâneos e Demandas Populares (PPGEduc) da Universidade Federal Rural do Rio de Janeiro (UFRRJ). Realizada com a turma Oséias de Carvalho (2010-2013), um dos principais objetivos da pesquisa foi estudar as ações do Laboratório de Artes a partir das experiências narradas por cada um dos educandos e educandas, nos seus cadernos reflexivos - que também são instrumentos pedagógicos desse Laboratório. Esta primeira turma foi formada por militantes dos movimentos sociais e sindicais, do campo e da cidade, e das populações quilombola, indígena e caiçara. $\mathrm{O}$ resultado imediato da pesquisa foi a criação da primeira vaga para docente de teatro da UFRRJ. A experiência que segue é fruto das reflexões da autora sobre as leituras das narrativas dos integrantes dessa primeira turma, sobre as narrativas das experiências teatrais, no âmbito do Laboratório de Artes do Curso.
\end{abstract}

Palavras-chave: Educação do Campo; Teatro; Formação de Educadores.

\section{ABSTRACT}

This text is a brief report of experience and comes from the master's research The theater in the Educator Training - Experiments with the Field Education of UFRRJ, defended in 2013 in the Posgraduate Program in Education, Contemporary Contexts and Popular Demands (PPGEduc) of the Federal Rural University of Rio de Janeiro (UFRRJ). Realized with the Class Oséias de Carvalho (2010-2013), one of the primary research objective was to study the actions of Art's Laboratory, by the narratives of the experiences wrote by each student, in their reflexive diaries (Cadernos Reflexivos) that also are pedagogical instruments of this Lab. This First Class was formed by social and syndicalist movements militants, from the fields and from the cities, and by Maroon, Indigenous and Caiçara population. The immediate result was the creation of the first position for a teacher of Theater of UFRRJ. The experience that follows is a fruit of my reflexions about reading the narratives of those students, about their theatrical experiences, in the ambit of Art's Laboratory.

Keywords: Field Education. Theater. Educator Training. 


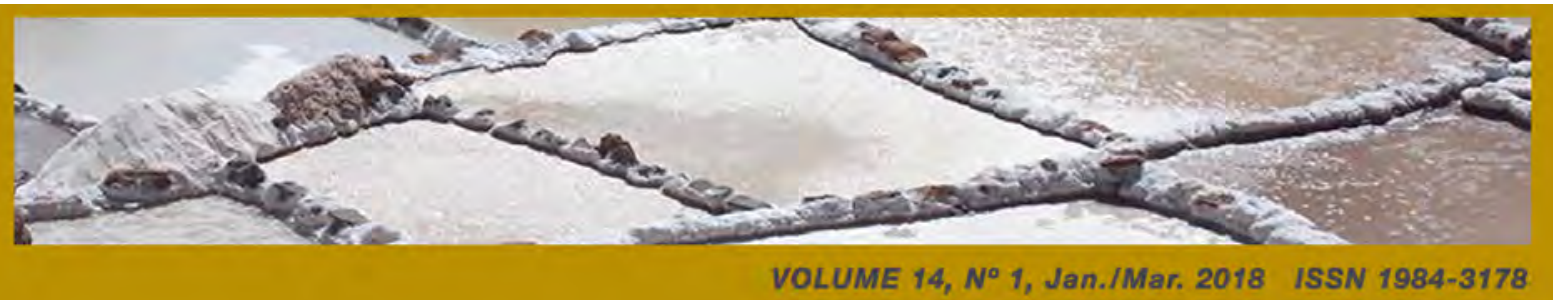

Este texto é fruto das reflexões que envolvem o processo de pesquisa e de escrita de uma dissertação na área da Educação, sobre teatro e formação de educadores. Uma das principais fontes são as narrativas sobre os experimentos teatrais manuscritas por educandas e educandos da primeira turma de Licenciatura em Educação do Campo $^{1}$ (LEC) da Universidade Federal Rural do Rio de Janeiro (UFRRJ), a Turma Oséias de Carvalho.

A dissertação foi defendida em 2013 e a Turma concluiu a graduação no mesmo ano. O tempo, no entanto, não nos separa. Aquela experiência vive em mim, não como algo que passou, mas como algo que ainda me passa, como experiência em processo, como a própria vida. Jorge Larrosa explica que a experiência é "algo que me passa", um acontecimento, um movimento de ida e de volta, cujo lugar do acontecimento sou eu. É movimento de ida, porque supõe uma "saída de mim mesma" e de volta, "porque afeta a mim" e a minha relação com o mundo (LARROSA, 2011, p. 5).

A cada vez que releio suas narrativas, outras sensações me afetam. E a primeira pergunta que me salta agora é, se é possível dedicar um relato de experiência? Penso que, se um relato de experiência é algo explicitamente atrelado à experiência, nada mais justo que agradecer as trocas imensuráveis que me formam e que levarei comigo por todo meu percurso. Não há relatos de experiências possíveis para expressar em palavras o que sinto. A única maneira que encontro agora é a de abrir esse texto agradecendo à Turma Oséias de Carvalho por tudo o que vivemos juntos.

\section{A TURMA OSÉIAS DE CARVALHO}

As narrativas das experiências aqui apresentadas remetem ao período de 2010 a 2013. Esta primeira turma foi criada em 2009, a partir de edital do Programa Nacional de Educação na Reforma Agrária (PRONERA) do Ministério do Desenvolvimento Agrário (MDA). A Licenciatura em Educação do Campo da Universidade Federal Rural do Rio de Janeiro foi desenvolvida com bases em estudos e experiências universitárias articuladas às práticas cotidianas das ações comunitárias e referenciada pelos princípios da Educação Popular. Esta é um exemplo em que o processo de conhecimento é vinculado aos espaços e tempos das classes que a constituem. A LEC também foi pensada e fundamentada nos princípios da 
educação para a formação docente, que, conforme explicitados pela Associação Nacional pela Formação dos Profissionais da Educação (ANFOPE), visa a: aplicar a interdisciplinaridade como fundamento epistemológico; valorizar o trabalho pedagógico coletivo; articular a formação teórica à prática; assumir a pesquisa como princípio de conhecimento e intervenção na realidade; e garantir flexibilidade curricular no curso (LEC, 2010, p. 11). ${ }^{2}$

Além disso, os objetivos específicos são dedicados a:

Capacitar para a docência multidisciplinar e gestão de educação básica em escolas do campo; Formar educadores que vinculem a educação à realidade; Potencializar a formação docente para a organização curricular por áreas de conhecimento nas Escolas do Campo (LEC, 2010, p. 11).

Herdeira de uma ideia de Educação Popular originada nos anos de 1960. No qual também foi criado o Movimento de Cultura Popular - MCP (1959), com núcleos para a valorização da cultura popular; o Movimento de Educação de Base - MEB, criado por setores progressistas da Igreja Católica, com membros da Juventude Universitária Católica - JUC (1961), com as escolas radiofônicas; e a Campanha "De Pé no Chão Também se Aprende a Ler", criada no mesmo ano. Roberto Schwarz destaca o método Paulo Freire de alfabetização que "não concebe a leitura como uma técnica indiferente, mas como força no jogo da dominação social" e que,

em consequência, procura acoplar o acesso do camponês à palavra escrita com a consciência de sua situação política. Os professores, que eram estudantes, iam às comunidades rurais e, a partir da experiência viva dos moradores, alinhavam assuntos e palavras-chave - "palavras geradoras", na terminologia de P.Freire - que serviriam simultaneamente para discussão e alfabetização (SCHWARZ, 2009, p. 19).

Com base nesse referencial teórico e prático, a LEC teve início no dia 20 de setembro de 2010. Com duração de três anos, suas 3.540 horas foram distribuídas por seis etapas, com base na pedagogia da alternância, partilhadas em Tempo Escola (TE) e Tempo Comunidade 


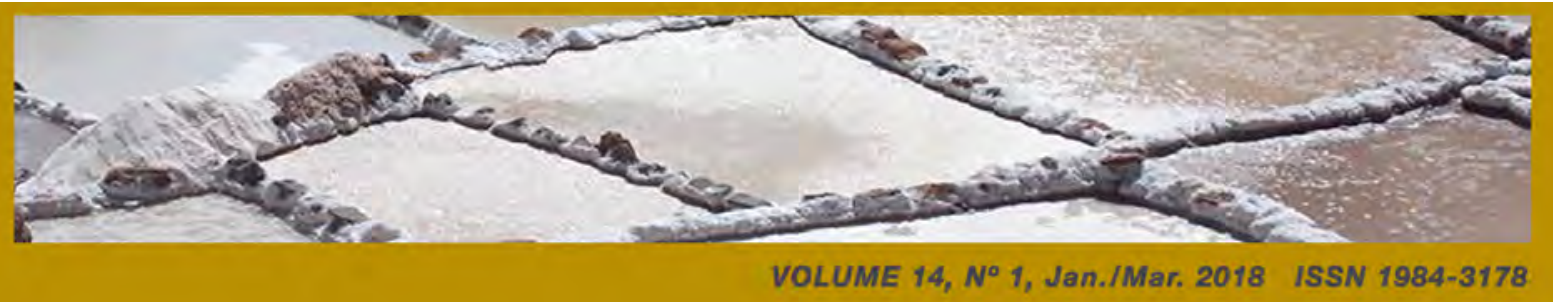

(TC).

O nome da turma é uma homenagem a Oséias José de Carvalho, reconhecido por seu engajamento na luta por Reforma Agrária na Baixada Fluminense do Rio de Janeiro e pai de uma educanda dessa turma que, assim como o pai, é militante do Movimento dos Trabalhadores Rurais Sem Terra - MST/RJ. A homenagem foi decidida em assembleia: “A cada companheiro tombado, nenhum minuto de silêncio, mas toda uma vida de luta".

O processo de seleção do curso foi divulgado por meio de Edital Público e teve como critérios: provas de conhecimentos culturais e gerais; redação sobre a realidade brasileira; carta com identificação de assentamento da Reforma Agrária e movimento de origem. Os critérios de avaliação foram estabelecidos seguindo os parâmetros da Comissão Especial de Acesso da UFRRJ.

O curso é criado com o intuito de desenvolver a dimensão educativa e o fazer pedagógico por meio da organização coletiva, tendo os movimentos sociais como exemplo de organicidade. A ênfase nas identidades e histórias de vida dos sujeitos e coletivos está articulada à produção e utilização de materiais didáticos para a atuação nas escolas do campo. Escolas como as que muitos desses educandos e educandas, hoje já graduados, também estudaram.

Com a experiência da LEC/Pronera, o Curso passou pelo processo de institucionalização em 2014, resguardando algumas de suas características principais, como a Pedagogia da Alternância e o Laboratório de Artes, por exemplo. Ressalto que o relato que segue é fruto da minha experiência junto a essa primeira turma, entre os anos de 2010 e 2013, sobretudo nas ações do Laboratório de Artes.

No Tempo Escola (TE), as disciplinas eram ministradas na instituição de ensino por educadoras e educadores da própria universidade, colaboradores voluntários e militantes de movimentos sociais. Cada TE durava aproximadamente oito semanas, mas variava conforme a carga horária de cada Etapa. O Tempo Comunidade (TC), tinha cerca de quinze semanas, ocorria nas comunidades das educandas e educandos, e buscava articular seus cotidianos de militância e pesquisa/estudos. A aplicação desse modelo visava a potencializar "a relação teoria e práxis, os estudos de realidade e o colocar-se do sujeito histórico no mundo. Em 


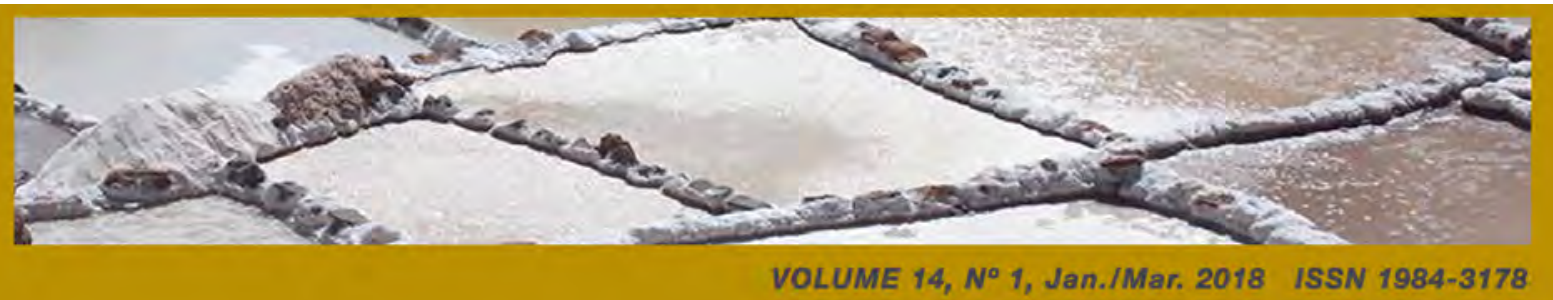

ambos os Tempos são realizados ensino, pesquisa, práticas pedagógicas diversas", como consta no Programa Político-Pedagógico (PPP) do Curso (LEC, 2010, p. 22).

O PPP do curso é pautado na ideia de uma educação que provoque os sujeitos "à discussão corajosa de sua problemática", que vale tanto para o corpo docente quanto para o corpo discente; que nos tire da zona de conforto para o confronto, pelo "diálogo constante" e nos revolva; nos predisponha a "constantes revisões" e reflexões; nos incite "a uma certa rebeldia", pois, “é na rebeldia em face das injustiças que nos afirmaremos!” (FREIRE, 1981, p. 89-90), lema da turma Oséias de Carvalho.

A primeira turma resultou de um movimento de integração no qual a educação converte o trabalho social em movimento político e no qual o corpo discente é compreendido e respeitado como sujeito do processo educacional (BRANDÃO, 2006, p. 55-57). A sua criação visava a projetar um amplo leque de instrumentos metodológicos e ferramentas pedagógicas para "oportunizar espaços formativos que extrapolem os muros das universidades, que levem o discente a interagir com a diversidade do campo, com os seus saberes e formas de construção e apropriação do conhecimento" (SANT'ANNA; MARQUES, 2015,p. 732).

O PPP foi criado colaborativamente, em reuniões periódicas, com referência nas demandas discutidas nos Seminários, Fóruns e Projetos sobre a Educação do Campo, Movimentos Sociais, Educação em Contextos Específicos, Juventude Rural, Agroecologia e Escola Ativa. Assim como as proposições de grupos de ensino, pesquisa e extensão sobre mundo rural, cultura e identidade.

O curso, nesta primeira turma, ofereceu duas habilitações: 1) Ciências Sociais e Humanidades; 2) Agroecologia e Segurança Alimentar. Herdando formas organizativas dos movimentos sociais e ao mesmo tempo experimentando outras, a turma Oséias de Carvalho foi composta por 54 educandos, de 15 Territórios, reunidos em cinco Regionais (Metropolitana, Sul Fluminense, Médio Paraíba, Norte Fluminense e Itapeva/SP). Foi incentivado a cada território, a elaboração de um Trabalho Integrado por Etapa. Este trabalho integrava a pesquisa de suas próprias histórias (movimentos e territórios), tecendo novas tramas com os registros das memórias sociais, num movimento "a contrapelo", a exemplo de 
Walter Benjamin.

\section{EXPERIMENTOS, DIMENSÕES ESTÉTICAS E FORMAÇÃO HUMANA}

A LEC desenvolveu instrumentos de ensino e aprendizagem que articulam as dimensões do complexo curricular às relações e concepções conceituais de organicidade, tempos e espaços, artes, linguagens e mídias, tais como os Trabalhos Integrados, elaborados a partir dos estudos das realidades de áreas de moradia e sobre os movimentos sociais aos quais os educandos integram; o Laboratório de Artes, que experimenta-se articulando audiovisual, teatro, produção textual e grupos de estudos; os Cadernos Reflexivos, nos quais eram registrados individualmente, as percepções das vivências pedagógicas relacionadas a cada Etapa.

Compreendemos os Cadernos Reflexivos como relatos dos processos formativos que têm potencial de formação crítica para contribuir na construção de novas subjetividades. E esta percepção deriva do entendimento de que a "mediação do conhecimento de si em sua existencialidade" pode possibilitar a reflexão de "oportunidades de tomada de consciência sobre diferentes registros de expressão e de representações de si, assim como sobre as dinâmicas que orientam sua formação" (JOSSO, 2007, p. 413-419).

O Laboratório de Artes está ativo desde 2010. Ganhou proporções e conquistou a turma e educadores, redesenhando-se e recriando-se a partir do planejado. Nele, articulamos cinema, teatro, fotografia, música, poesia e grupos de estudo, acendendo a multiplicidade das leituras de mundo a partir dos experimentos com: a) narrativas (relatos das memórias); b) linguagens visuais, audiovisuais e teatrais. O objetivo inicial era experimentar ler e reler o mundo com diferentes instrumentos, à exemplo de Paulo Freire.

Ao articular teatro, cinema, fotografia, poesia, narrativas, instrumentos musicais, com a formação docente, compreendemos no decorrer desses três anos, que as qualidades do Laboratório podem potencializar uma renovação formativa dos sujeitos envolvidos no processo de ensino-aprendizagem, com formação crítica de bases teóricas e dimensões 


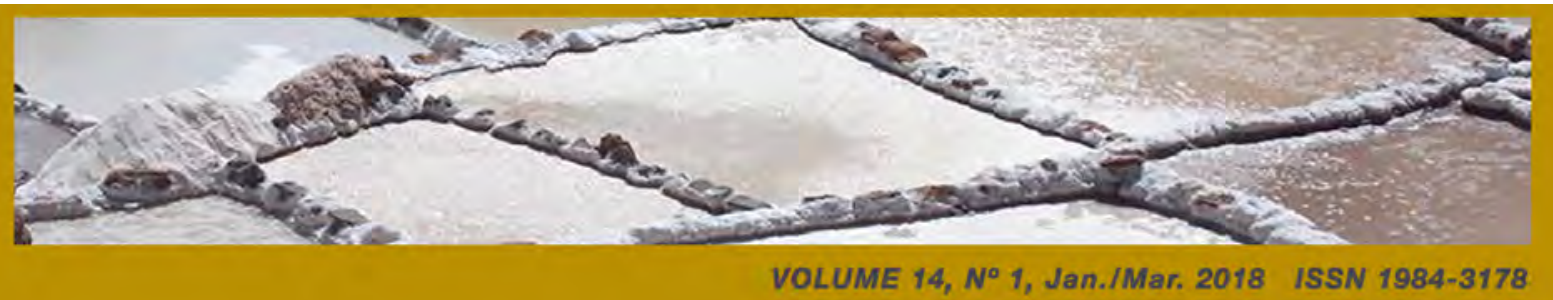

estéticas. As suas atividades fortalecem os componentes curriculares tradicionais (aulas e seminários). Além de oficinas, o Laboratório integra o conjunto de registros visuais (fotografias), audiovisuais (filmagens) e escritos (cadernos reflexivos). A partir dessa experiência, constatamos que o Laboratório realizou, ao menos, dois tipos de trabalho pedagógico: a) com relatos de vida narrados e as histórias de lutas dos movimentos; b) com as leituras e com as experiências envolvendo outras linguagens.

Na primeira etapa do curso, de setembro a novembro de 2010, as atividades do Laboratório foram constituídas pela exibição de filmes seguida por diálogos e com registros escritos pelos educandos (a); memórias, a partir de filmagens e fotografias do cotidiano da LEC pelos educandos (b).

Sobre o trabalho com o cinema em forma de aula, Gabriel Perissé aponta que "a sétima arte é educativa em pelo menos três direções". Uma se dá "quando vemos o ensino tematizado pelo cinema". A outra é "quando utilizamos o cinema para ensinar determinados saberes”. E ainda, “quando ensinamos a arte de fazer cinema” (PERISSÉ, 2009, p. 69). Nesta etapa, as exibições de filmes tiveram como tema a cultura popular, tendo como títulos: Narradores de Javé, de Eliane Caffé (2003); Ave-Poesia, de Rosemberg Cariry (2009), sobre o poeta Patativa do Assaré; Muita gente desconhece "João do Vale", de Werinton Kermes (2005), sobre o cantor Maranhense que ganhou evidência com o Show Opinião; Mestre Bimba: Capoeira iluminada, de Luis Fernando Goulart (2007); o curta-metragem Campo Branco, de Telmo de Carvalho (1997), sobre a relação do homem nordestino com o solo e dois capítulos iniciais da Era das Utopias, minissérie exibida pela TV Brasil em 2009, idealizada e dirigida por Silvio Tendler.

O Tempo Comunidade 1, de dezembro de 2010 a março de 2011, foi marcado pelo trabalho com as fotografias do livro Terra de Sebastião Salgado e, pelas entrevistas realizadas pelos educandos com os membros dos movimentos sociais e integrantes das suas comunidades. Constatamos que articular o registro das histórias individuais nas lutas travadas em coletivo às linguagens visuais e verbais, fortaleceu os exercícios de leituras e produções textuais.

No Tempo Escola da Etapa 2, de março a maio de 2011, as linguagens do audiovisual 


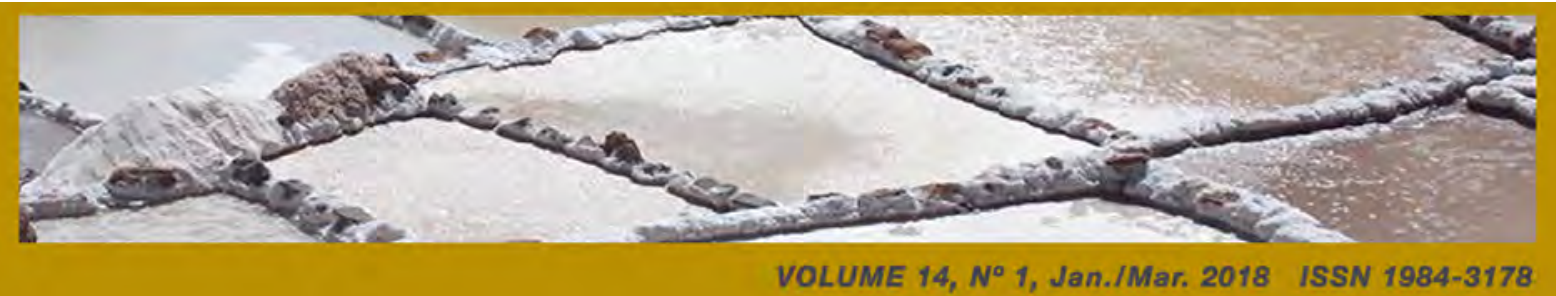

e do teatro tiveram como tema as criações dos movimentos de educação e cultura popular dos anos de 1960, aprofundando o que foi abordado na Etapa 1. Na semana inicial da Etapa 2, a Companhia do Latão (São Paulo), à convite do Laboratório, apresentou o Ato I da Ópera dos vivos - Sociedade Mortuária: Uma peça Camponesa. Nas semanas seguintes foram exibidos e discutidos os filmes Eles não usam black-tie, de Leon Hirszman (1981), inspirado na peça de Gianfrancesco Guarnieri (1958) e Cabra Marcado para morrer, de Eduardo Coutinho (1984). Conduzimos, a cineasta e dramaturga Carol Pitzer, Ângela Morais, educanda da LEC e militante do Movimento de Ocupação Urbana (Quilombo das Guerreiras) e eu, atividades teatrais que culminaram em três esquetes apresentadas pela turma ao final desse Tempo Escola.

O terceiro TE (de setembro a novembro de 2011) foi marcado pelas Oficinas de Leituras sobre história da Educação Popular; produção textual e edição em audiovisual. No Tempo Escola 4 (de abril a junho de 2012) foi exibido o filme Noviembre, de Achero Mañas (2003); a oficina de construção de tambor com introdução às histórias do movimento negro no Brasil; assim como a oficina de arte e política com fanzine de colagens sobre Educação do Campo; além da apresentação do Théâtre du Soleil (França), com o espetáculo Os Náufragos da Louca Esperança.

No quinto Tempo Escola (de setembro a novembro de 2012), os educandos optaram por voltar às especificidades do cinema no âmbito da luta social. Os títulos exibidos foram o Baader Meinhof, do diretor Uli Edel (2008) e Soy Cuba, de Mikhail Kalatozov (1964). Em outubro foi apresentado o teatro Terra: A História de João da Boa Morte, Cabra Marcado para morrer, com o grupo Ícaros do Vale (Vale do Jequitinhonha-Minas Gerais).

O sexto TE (de junho a setembro de 2013), a Etapa de conclusão da LEC/UFRRJ/Pronera, os educandos participaram de debate sobre a atualidade de Brecht, uma realização do Grupo de Estudos sobre Teatro Político e do Centro de Teatro do Oprimido (Rio de Janeiro); assistiram a peça O Patrão Cordial, seguido de conversa com a Companhia do Latão; concluíram as colagens para o fanzine sobre a Educação do Campo e ensaiaram a remontagem do Arena Conta Zumbi, A LEC Conta Zumbi.

O Laboratório de Artes da Licenciatura em Educação do Campo foi criado por um 


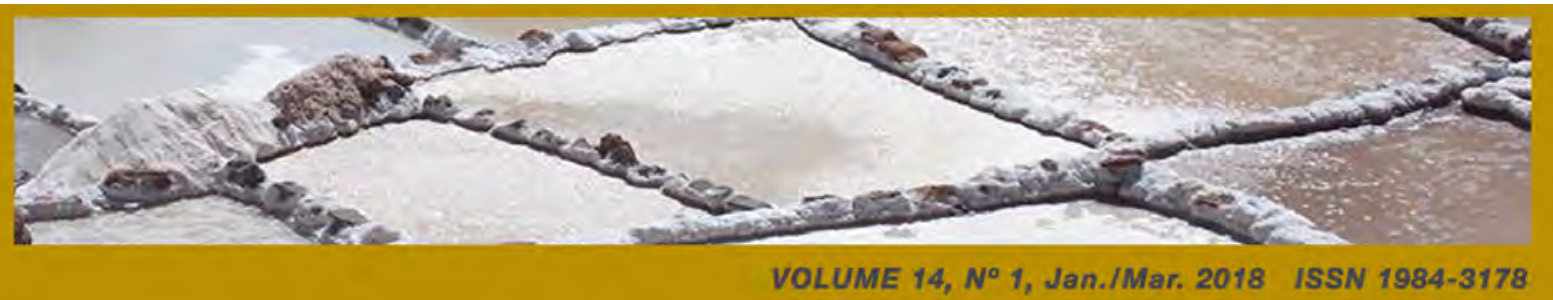

colegiado que acredita que o defrontar-se com a arte educa na medida em que os sentidos, para além da razão técnica, numa via de mão dupla, são impactados e impactam pelo contato e estranhamento, pois "ler uma obra de arte consiste em criar com ela, a partir dela e além dela: desdobramentos do encontro" (PERISSÉ, 2009, p. 42).

Com a introdução das diferentes linguagens na formação de educadores, compreendemos que a LEC contribui com a reflexão da própria produção do conhecimento, buscando uma polifonia no processo formativo. Assim, nos dedicamos ao diferencial de uma formação que envolve vivenciar os movimentos sociais nas instâncias educacionais de nível superior.

\subsection{COMPANHEIRAS E COMPANHEIROS - REFERÊNCIAS TEATRAIS}

O processo de pesquisa e escrita da dissertação foi intensamente dedicado a leituras, conversas e experiências teatrais. Das leituras referenciadas no texto final apresentado ao Programa de Pós-graduação (PPGEduc/UFRRJ), destaco Estudos sobre teatro, de Bertolt Brecht, 1978; o livro organizado por Wolfgang Bader (1987) Brecht no Brasil Experiências e Influências; Brecht - a estética do teatro, de Gerd Borheim (1992); a obra de Anatol Rosenfeld, alguns escritos de Frederic Jameson, de Fernado Peixoto e Sábato Magaldi. Os escritos da Companhia do Latão têm sido, desde lá, da maior importância para meus estudos sobre teatro político, dos quais destaco Introdução ao teatro dialético: experimentos da Companhia do Latão, organizado pelo seu diretor, Sérgio de Carvalho (2009). Penso que os escritos de Iná Camargo Costa são indispensáveis para quem deseja se dedicar ao tema. Na dissertação, me dediquei, sobretudo, ao Nem uma lágrima. Teatro épico em perspectiva dialética (2012). Importante comentar que a leitura de Augusto Boal é mister para estudar o teatro político brasileiro. Essas são algumas das referências que estudei durante a escrita da dissertação de mestrado e que trago comigo no processo de pesquisa atual e, muito provavelmente, seremos companheiras e companheiros de longa jornada.

\section{AS NARRATIVAS DOS EXPERIMENTOS TEATRAIS}




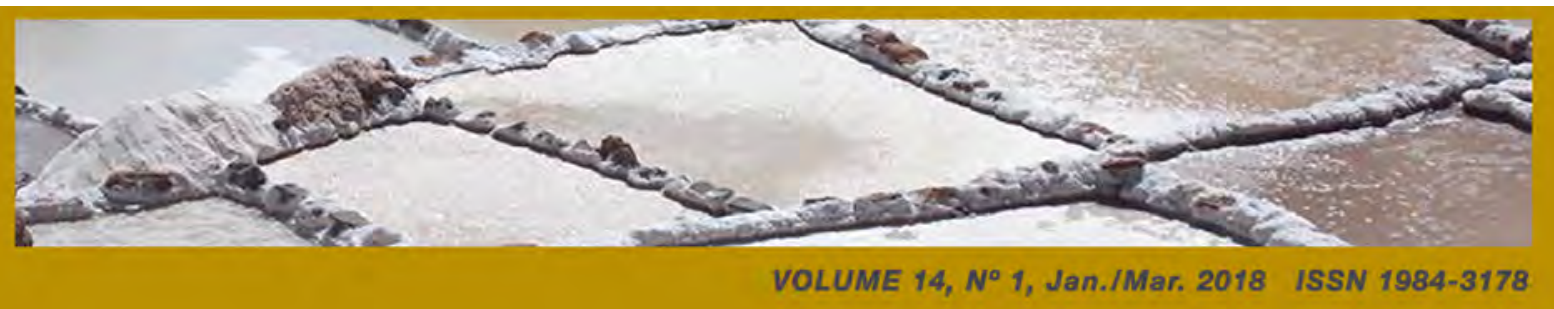

Foi maravilhoso, emocionante, motivador. Foi minha estreia no teatro. Primeira vez que assisti uma peça. Amei! [...] Eles contavam a história de um homem que seria enterrado sem caixão. [...] Na hora em que, no meio da peça a moça pergunta quem quer continuar lutando contra o latifúndio levante o braço, todos que assistiam a peça em cima do palco levantaram a mão. [...] Finalizamos com gritos de ordem Reforma agrária quando e juventude que ousa lutar constrói o poder popular. Aí os atores e nós LEC choramos e nos abraçamos. (M, do assentamento Marapicu, em Nova Iguaçu).

A narrativa acima é sobre o Ato I da Ópera dos Vivos da Companhia do Latão, em 2011. Exceto duas, todas as narrativas que constam neste artigo provêm dos Cadernos Reflexivos. Nesses cadernos constam os relatos do cotidiano acadêmico e de militância, questões de afeto e de arte, as vivências com as disciplinas, com o colegiado, reuniões, inquietudes e paixões.

Os Cadernos Reflexivos foram divididos em Tempo Escola e Tempo Comunidade. Aqui os escritos são sobre as atividades do Laboratório, especialmente sobre o teatro, desde 2010 até 2013. Ou seja, do ingresso à conclusão do curso, com ênfase no Tempo Escola de cada etapa.

Os narradores e narradoras são identificados pela letra do primeiro nome, seguida do movimento social ao qual pertencem e suas localidades. A escolha por essa forma de identificação foi feita para que se reconheçam. Ao todo, foram analisadas 43 pastas, cada pasta contém de dois a seis cadernos reflexivos. Cabe comentar que nem todos entregaram seus cadernos e há, por alguns, Etapas inteiras em silêncio. Da mesma maneira, nem todas as ações teatrais foram comentadas.

Lemos as dimensões educativas do teatro pelas narrativas dos educandos, com a perspectiva de que "o narrador colhe o que narra na experiência, própria ou relatada. E transforma isso outra vez em experiência dos que ouvem sua história” (BENJAMIN, 2012, p. 217). Consideramos a leitura dos escritos fundamental para a contribuição com a pesquisa sobre a Educação do Campo, assim como sobre a formação de educadores reflexivos. As narrativas da Turma Oséias de Carvalho são acúmulos a serem revisitados para a compreensão das lutas dos movimentos sociais pela educação e pela luta de permanência e melhoria das escolas do campo, assim como para o pensamento sobre a importância da arte 
para a formação humana.

Alguns dias após a apresentação da Companhia do Latão, recebi da educanda Cida Santos (Pinheiral) uma dedicatória poética intitulada Aos Companheiros do Latão:

A Companhia do Latão proporcionou a nós, alunos da Educação do Campo, uma das mais belas, importantes e sublimes aulas de nossas vidas.

$\mathrm{Na}$ peça "Ópera dos Vivos", é como se a gente estivesse vivendo em Galileia, tal a magia e o encantamento dos atores.

Transportamo-nos no tempo e no espaço, nos indignamos com aquele patrão frio e opressor. Choramos com aquela viúva guerreira, que lutava por um caixão para enterrar o seu marido. Choramos por nossos mortos.

Nesse contexto os personagens gritavam com a voz embargada, tinham que se libertar daquelas correntes.

Saltava-lhes aos olhos a angústia e o terror. Era um tempo de aflição e de capitalismo selvagem. A arte de ensinar estava lá, na graciosidade da professora, na garra e no sofrimento de uma mulher lutadora.

$\mathrm{Na}$ "Ópera dos vivos" a tragédia da Galileia atravessou-nos o peito, deu um nó na garganta e ecoou-nos um grito de liberdade.

As lágrimas rolaram e ficou um vazio. Um vazio que precisa ser preenchido com a continuidade da luta, porque os filhos desse Brasil imenso, assim como os filhos de Elizabete, pulsam por uma sociedade mais digna e mais justa.

A nossa carne treme, as nossas emoções misturam, não há mais atores e público, mas sim seres paralisados, exaustos, com o grito preso na garganta e a alma livre. Parece que os espíritos dos que lutam tombavam ali, nos chamando.

Levantamos os braços e dissemos: sim, nós também estamos aqui nessa caminhada, também somos sem terra, também somos povo sofredor e explorado, também temos os nossos mártires.

O silêncio paralisou o tempo, os aplausos acordou o vento, aquele momento único, nunca visto nada igual, ficará em nossas memórias para sempre.

“[...] Viva as Ligas Camponesas! Viva a Companhia do Latão! Viva a LEC!” Esta é a narrativa poética da educanda Cida Santos, em 04 de maio de 2011. Mas, não estava nos cadernos reflexivos. É folha avulsa e foi entregue em mãos, distribuída não só a mim, mas 
também a toda a turma. Cida é a única educanda citada com nome e sobrenome. Essa poesia foi escrita e entregue com a finalidade de registrar publicamente sua experiência.

A narrativa, por ser a representação das trajetórias percorridas pelo narrador, pode vir a ser um elemento transformador da realidade (JOSSO, 2007, p.419). Se da experiência surge a narrativa, esta também pode contribuir na produção de novas experiências. E ao se produzirem, se confrontam e, portanto, se relacionam dialeticamente. Vejamos o que o educando T (assentamento Celso Daniel - Macaé) comenta no seu caderno reflexivo sobre a peça que não viu:

houve uma peça de teatro também, chamada Ópera dos vivos, eu não cheguei a ir mas os depoimentos dos meus companheiros, me passaram uma tal emoção que cheguei a me arrepiar, foi uma sensação semelhante quando eu vejo um filme falando da luta dos movimentos.

A produção das narrativas ainda requer que nos confrontemos com o que é dito e o que é silenciado no processo de expressão do sujeito em ambientes coletivos e sua importância nos processos de aprendizagem. Esse aspecto é reforçado pela fala de J (assentamento Terra Prometida - Nova Iguaçu), ao ponderar suas experiências nas oficinas de teatro: "Eu sou muito nervosa para falar: eu entro na sala, eu entro muda e saio muda [...] Mas quando eu me envolvo no teatro...". Ainda sobre as oficinas de teatro, L (Cooperativa Magé - Piabetá) comenta: "para sentir o que o outro sente você tem que se colocar no lugar do outro. E quando você representa, você se julga, você se avalia, avalia o outro, o que ele sentiu, o que ele não sentiu e o que você poderia ser". L (Coop. Magé - Piabetá) afirma ainda "fiquei muito feliz em termos em nosso currículo aulas de teatro. Gosto do teatro. Já fiz alguns trabalhos nas escolas e em reuniões religiosas". Percebemos então, a importância da incorporação da linguagem teatral na ampliação das potencialidades dos sujeitos no processo de ensinoaprendizagem. Privilegiar a arte do diálogo e as relações entre a formação dos educandos e suas histórias de vida está previsto no PPP do Curso (LEC, 2010, p. 17).

Neste dia a Turma da LEC foi presenteada com uma oportunidade de ter uma das maiores experiências [...]. Nesta peça o público fica muito próximo 


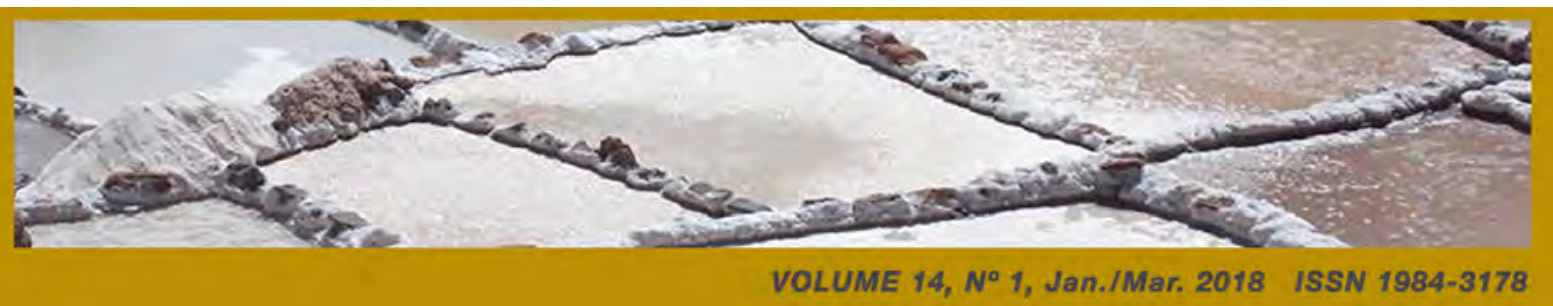

aos atores (praticamente dentro do cenário) quebrando assim uma relação vertical estabelecida nos outros teatros que eu tinha visto. Isto fazia com que parecesse que estávamos vivendo a situação encenada [...] a luta trazida na peça é uma luta que vivenciamos hoje em nossos movimentos sociais. [...] a performance da peça, o entrosamento dos atores, o uso da música, juntamente com a narração sem que um prejudicasse o outro e a forma como nos olhavam nos momentos forte fez com que todos se emocionassem e interagissem.

Percebamos com este relato (não identificado), uma associação do ato às lutas dos movimentos e uma análise da forma do teatro épico, quando afirma que "o entrosamento dos atores, o uso da música da encenação juntamente com a narrativa". Para Benjamin, a produção de narrativas é "uma forma artesanal de comunicação" que não exige ao narrador comunicar o "puro em si' da coisa narrada" como num relatório. A narrativa colhe a passagem de vida do narrador e a revela. De tal modo que imprime a "marca do narrador" na narrativa, "como a mão do oleiro na argila do vaso" (BENJAMIN, 2012, p. 221). É em busca dessas impressões que procuramos entender o processo, lendo a turma como fonte. Vejamos o que conta a educanda C (Quilombo das Guerreiras - Rio de Janeiro) descreve o "Giro pela Cultura", como intitula a página do seu caderno reflexivo:

os filmes Cabra Marcado pra Morrer e Eles não usam black-tie e o teatro Ópera dos Vivos da Companhia do Latão foram muito bons por trazer cultura para nós educandos, que muitas das vezes não temos tempo, nem dinheiro para ter acesso a cultura, tão importante para a nossa formação.

E no espaço artesanal das relações entre educadores e educandos, onde "os movimentos sociais são os protagonistas dessa Licenciatura”, como afirma A (Quilombo Santa Rita do Bracuí - Angra dos Reis), é que se tecem esses diálogos que fomentam a práxis para a construção de uma educação dialógica e, portanto, reflexiva. A educanda A (Coop. Magé - Piabetá) descreve:

O que mais me marcou e sensibilizou essa semana foi a Ópera dos Vivos. Já começou diferente: não sentamos na plateia, fomos para o palco. 


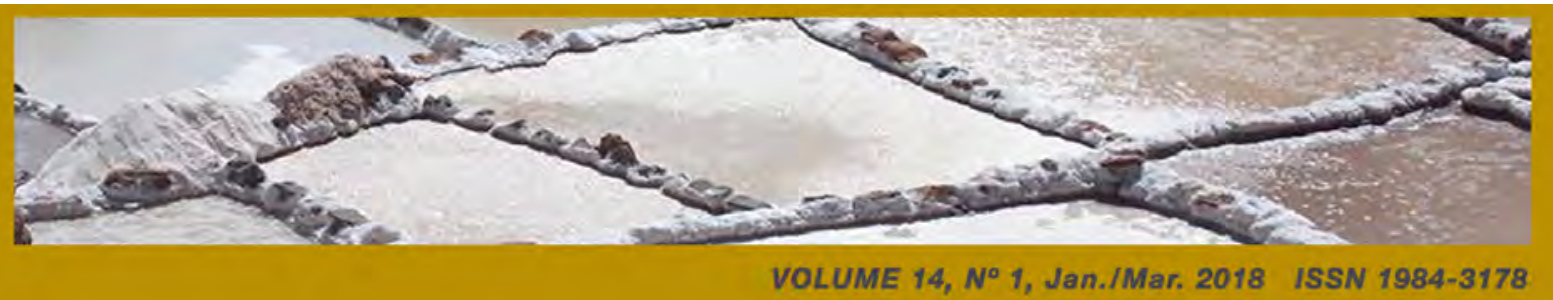

Durante toda a peça, fiquei muito emocionada com a aproximação dos atores. A sensação era de que estava participando da peça. [...] a frase que ficou marcada na minha mente foi quando a empregada estava aprendendo a ler e falou que "um lápis pesa mais que uma enxada". A cena final também foi linda. Parece até aquela foto de Sebastião Salgado.

Ainda sobre a Camponesa, A (Quilombo Santa Rita do Bracuí - Angra dos Reis) comenta: "eu sei pouco sobre a história da Liga Camponesa. Foi graças a essa peça e ao filme Cabra Marcado pra Morrer eu pude aprender mais". A educanda S, da Coop. Magé, em Piabetá, narrou: “foi a primeira vez que assisti uma peça de teatro com atores profissionais!". A (Assentamento Presidente Lula - Rio das Ostras) escreveu: "é a primeira vez que assisto uma peça de teatro. Já havia assistido sim, na televisão: só que este teatro é diferente. Não tem plateia". Já o educando C (Sindicato Xerém - Duque de Caxias) comentou "o tempo todo tínhamos vontade de interagir com os atores".

O Laboratório de Artes, conforme indicado no PPP, surge para articular os componentes curriculares mais tradicionais às diferentes linguagens e formas de produção de conhecimento. Estes, acreditamos que têm papel pedagógico essencial na trajetória dos educandos. E, se "quem escuta uma história está em companhia do narrador" (BENJAMIN, 2012, p. 230), convidamos a viver junto a essas experiências, aqui narradas pela Turma Oséias de Carvalho, visando a reflexão sobre os conteúdos das ações do Laboratório e a forma como foram e ainda são experimentados.

Ao articular o filme Cabra Marcado para morrer com A Sociedade Mortuária (Camponesa), em diálogo com os trabalhos sobre educação e cultura populares e objetivando a interlocução da luta protagonizada pelas Ligas Camponesas, antes e hoje, o Laboratório realizou, de 14 de março a 06 de maio de 2011, dinâmicas simultâneas de teatro com base em três estéticas: Teatro Épico, Teatro Aristotélico e Teatro do Oprimido. Essas dinâmicas, somadas às leituras, movimentou a Turma nas criações de esquetes que foram apresentadas no encerramento do TE 2.

Para a apresentação das estéticas teatrais, a turma foi dividida em três grandes grupos, no Centro de Atenção Integral à Criança e ao Adolescente - CAIC Paulo Darcoso Filho. As estéticas foram experimentadas em dinâmicas simultâneas. Ou seja, enquanto a cineasta e 
dramaturga Carol Pitzer se dedicava a um dos grupos para destrinchar o teatro aristotélico; A educanda e militante do Quilombo das Guerreiras, Ângela de Morais, trabalhou com os jogos teatrais do Oprimido, de Augusto Boal. Eu me aterei à que apresentei, sobre o teatro épico, com jogos e narrativas, coros e músicas. Das narrativas dos educandos destaco um relato de insatisfação ante ao desafio. A educanda M (Assentamento Presidente Lula - Rio das Ostras) desabafa:

Fazer teatro ou não? [...] Foi assim que me senti. Como se as meninas estivessem me obrigando a fazer algo que eu não tinha que aprender, agora percebo que no fundo sinto que a arte não é pra mim! E acabo me irritando com quem insiste em me abrir as portas de outro mundo. [...] E pior, impor: "O teatro não é opcional e será apresentado dia..." Odiei a frase, a postura naquela hora. [...] a sorte é que elas são determinadas e sabiam o tempo todo o que queriam. [...] Nós, de fato só entendemos meia hora antes da apresentação. Por pressão, coragem, irresponsabilidade ou um pouco de tudo junto! Mas, quando decidimos coletivamente fomos determinados. E foi um desafio maravilhoso! Eu não tenho palavras para explicar a emoção, a sensação de realização.

“Abrir as portas de outro mundo!". Nosso objetivo, neste coletivo de educadoras, era mostrar que a arte pode e deve estar disponível para quem quiser. O educando $\mathrm{M}$ (Assentamento Celso Daniel - Macaé) relata: "fizemos oficina de teatro dividida em três ambientes. Fiquei encantado com as técnicas. [...] Pude sentir meu corpo, ouvir o som, olhar nos olhos dos companheiros".

Desenvolvi com os três grupos, a arte de representar, pelo jogo e com improviso. A ideia inicial era trabalhar a desinibição e a confiança, com trocas de olhares e toques musicais. Inspirado nos escritos de Schiller ${ }^{3}$ sobre a educação estética, Marcuse (1972) sugere o jogo como impulso lúdico, como dito anteriormente, observando o jogo como "a própria vida, como a manifestação de uma existência sem medo nem ansiedade" (MARCUSE, 1972, p. 166).

Após alguns encontros intercalando teoria e prática, decidimos com a turma que seriam realizadas três esquetes e eles tinham liberdade para escolher as estéticas e renovar e inventar. O tema foi o preconceito, sugerido como exemplo e adotado pela turma. Esse tema 


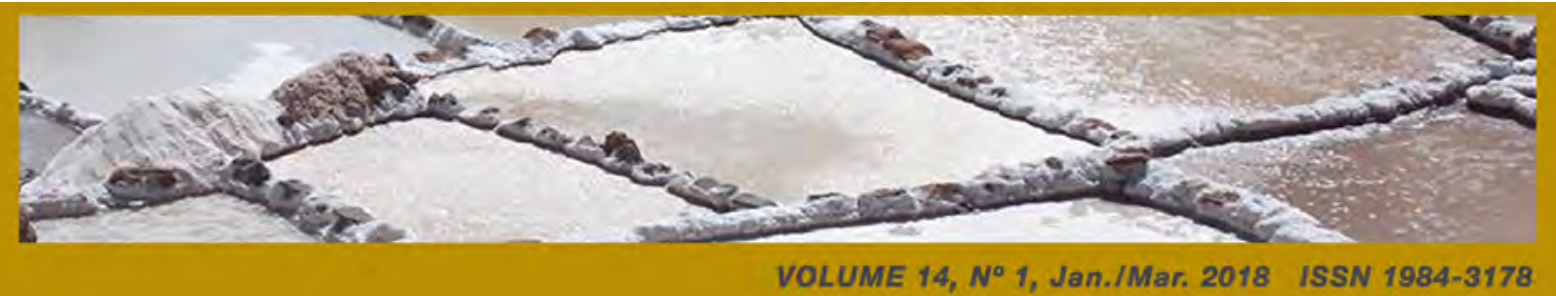

foi abordado em suas mais variadas experiências sociais: a diversidade etnicorracial, a diversidade sexual e a relação dos militantes dos movimentos sociais como estudantes de uma universidade pública. A turma teve total liberdade artística de adaptação e exploração das estéticas, o que revelou as expressões das próprias histórias.

Durante as apresentações das esquetes os educandos se revelaram. Eu recordo alguns quadros. A primeira esquete apresentada teve a narração da professora, personagem de $\mathrm{E}$ (Assentamento Presidente Lula - Rio das Ostras) junto ao coringa, personagem de N (Vale do Ribeira - SP) que juntos apontavam vários preconceitos. E e $\mathrm{N}$ entravam e saiam de cena a cada quadro apresentado. Após as cenas, os atores se escondiam debaixo de um pano. J (Assentamento Zumbi dos Palmares - Campos dos Goyatacazes) fez um personagem xingado e violentado num ponto de ônibus, porque usava camisa e boné do MST. M (Assentamento Celso Daniel - Macaé) interpretou uma mulher madura que namorava o jovem $\mathrm{S}$ (Assentamento Zumbi dos Palmares - Campos dos Goyatacazes) e foram rechaçados na rua pela diferença de idade. A educanda J (Cooperativa Univerde - Nova Iguaçu) fez trio com $\mathrm{R}$ (Quilombo das Guerreiras - Rio de Janeiro) e D (Assentamento Cambucaes - Silva Jardim): quando a personagem de $\mathrm{J}$ encontra sua amiga de infância (D) namorando $\mathrm{R}, \mathrm{J}$ tem um acesso de loucura e começa a dizer que se ele "é preto e não pode ser um homem de verdade". D, então pergunta a J o que ela pensa que é e J responde: “Eu sou quase branca, viu?”.

Recordo também de M (Marapicu - Nova Iguaçu), a dona de casa violentada pelo marido - D (Mutirão da Paz - Pinheiral) - e mãe da menina R (Zumbi dos Palmares - Campos dos Goyatacazes), que namorava a personagem de G (Presidente Lula - Rio das Ostras). D (o pai) é avisado pela fofoqueira apresentada por Ac (Zumbi dos Palmares - Campos dos Goyatacazes) sobre o namoro da filha com uma menina. O pai surra a filha e bane-a de casa. A mãe apanha por defender e recorre à Justiça para denunciar os maus tratos. Ao encerrar a esquete, os educandos relatam que tiveram inspiração em notícia de morte e banimento publicada em jornal da região central do país, e leem a notícia.

A última esquete foi um relato do preconceito vivido pela turma no ato de celebração do centenário da Universidade, em 20 de agosto de 2010. Os educandos narram o que vivenciaram, quando chegaram com as bandeiras e foram isolados pela guarda, junto às coordenadoras do curso. Tiveram que retirar os mastros das bandeiras e não mais entoarem 


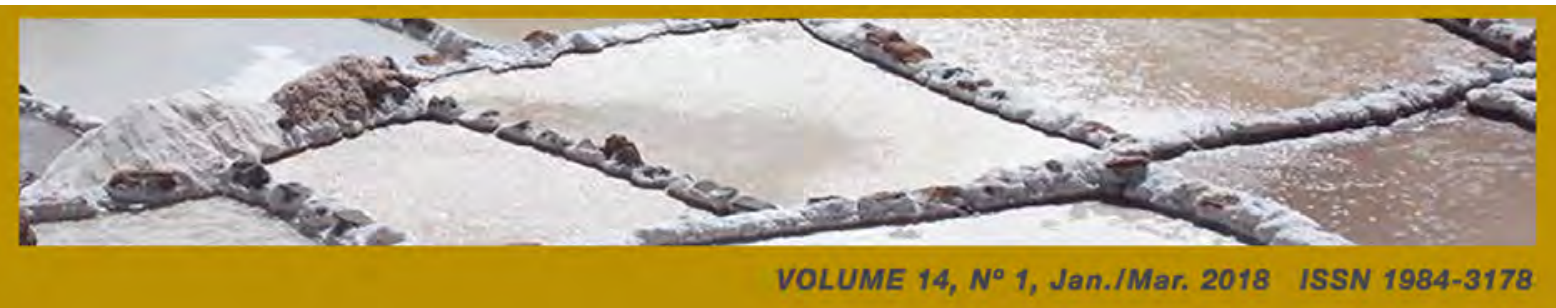

palavras de ordem. Durante um jogo conduzido pelos alunos de outros cursos, com orientação do Centro de Arte e Cultura da universidade, numa disputa de cursos e profissões, a LEC tinha um guarda à sua frente, um atrás e outro ao lado. Os educandos da LEC repudiaram aquele gesto e retrataram esse episódio para que se lembrem de que numa "universidade com história de 'cota de boi', havia também uma turma de sem terra".

Além da apresentação citada, as esquetes também foram apresentadas no III Seminário Discente do Programa de Pós-graduação em Educação - PPGEduc/UFRRJ, entre 26 e 28 de setembro de 2011, no salão azul, do P1 (pavilhão central), campus Seropédica. A educanda D (Assentamento Cambucaes - Silva Jardim), narra: "apresentamos o teatro da nossa turma no Seminário. Foi sensacional. A turma interagiu. Foi um dia maravilhoso”. Como como aponta Lambert (1993), acreditamos também que

na contemplação estética, a nossa sensibilidade e imaginação concordam, entram num jogo harmônico com a nossa inteligência, sem recurso a conceitos. Esse jogo harmonioso entre as nossas funções mentais, essa integração de todas as capacidades do homem suscita o prazer estético, e o gosto julga o objeto a mercê desse agrado (ou desagrado) (LAMBERT, 1993, p. 20).

Em outubro de 2012, a Companhia de teatro Ícaros do Vale, do Vale do Jequitinhonha, Minas Gerais, apresentou em forma de arena, o espetáculo Terra - A História de João BoaMorte, Cabra Marcado para morrer, inspirada na poesia de Ferreira Gullar (1962). Vejamos a narrativa da educanda Mb, do assentamento Marapicu, em Nova Iguaçu:

A apresentação do teatro retratando os assassinatos dos sem terra e líderes do povo. A peça foi defronte ao P1. Foi emocionante. Com bandeiras do MST, Via Campesina, terra, sementes... Choramos durante a peça e logo após o término [...] um grito de ordem: Pátria Livre que estremeceu todo o meu corpo. Fiquei três minutos tremendo de emoção e gritei: Turma Oséias de Carvalho. [...] Não seremos mais os mesmos.

As narrativas se travam permeando as experiências individuais com as experiências vividas em coletivo. Quando nos colocamos para dialogar com a produção de narrativas dos educandos, devemos enfrentar as diferenças de relações entre a linguagem oral e a escrita. 


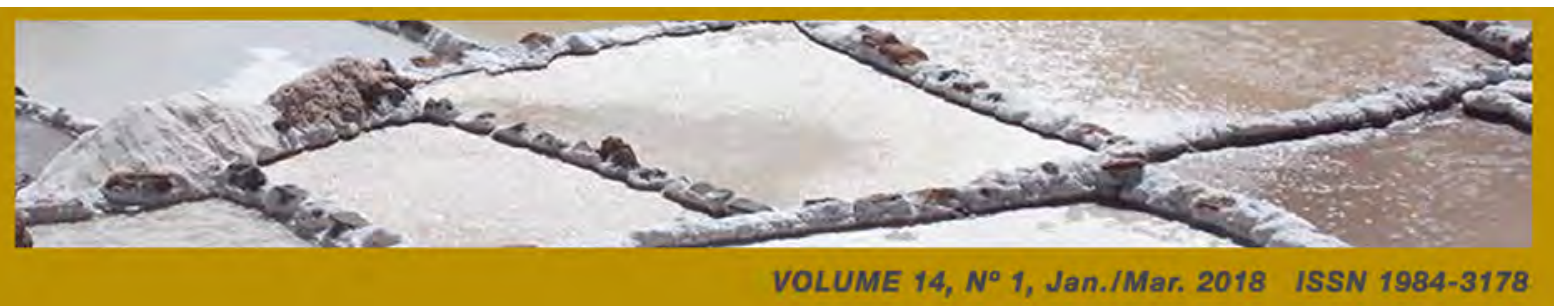

Algumas características de fluidez, expressões, gestos, ênfases, repetição de palavras das narrativas orais contrapõem-se às qualidades mais formais da linguagem escrita, evidenciando as especificidades das narrativas das formas e conteúdos que expressam.

A referência ao passado mantém coeso o coletivo a que se pertence. Pollak (1989) utiliza-se do conceito de "enquadramento da memória" para descrever as tentativas da memória coletiva em salvaguardar e fazer manutenções do passado. Pollak concorda com Halbwachs (1990), no que se refere ao processo de "negociação" entre memória coletiva e memória individual. A memória coletiva é um território em disputa, sempre produzida pelas relações de poder:

$\mathrm{O}$ trabalho de enquadramento da memória se alimenta do material fornecido pela história. [...] Esse trabalho reinterpreta incessantemente o passado em função dos combates do presente e do futuro. Mas, assim como a exigência de justificação discutida acima limita a falsificação pura e simples do passado na sua reconstrução política, o trabalho permanente de reinterpretação do passado é contido por uma exigência de credibilidade que depende da coerência dos discursos sucessivos [...] [pois] o que está em jogo na memória é também o sentido e identidade individual e do grupo (POLLAK, 1989, p. 10).

Ao longo dos três anos, enquanto sujeito coletivo, a LEC fez manifestações dentro e fora da universidade, registrando sua memória em vídeos, fotografias, encenações teatrais, poesias que imprimem no cotidiano da universidade as suas características próprias. A convivência com os educandos, com suas bandeiras, camisas e bonés instrui sobre os movimentos sociais aos quais pertencem. Com isso, percebemos que a LEC educa, age e representa suas vivências nas diferentes comunidades e manifestações políticas.

O legado da LEC à UFRRJ, em termos de formação humana, é política e cultural, caracterizado principalmente pela permanência da Pedagogia da Alternância e por abrir suas portas a sujeitos militantes de movimentos sociais dos campos e das cidades que lutam por reconhecimento e justiça social. Com a institucionalização do Curso, esta pesquisa contribuiu, sobretudo, para a criação da primeira vaga para docente efetivo de Teatro da UFRRJ.

Buscamos caminhos, experimentamos, nos repetimos, nos equivocamos, pelas 
dimensões estéticas e educativas do teatro e da arte em suas diferentes linguagens. Sem nos eximirmos dos enfrentamentos políticos, científicos e conceituais, e pontuando a escolha de expor uma pesquisa conforme seu conteúdo. Seguimos com os olhos atentos, com os pés na terra e a cabeça nas nuvens, como sugeriu Theodor Adorno. Em outras palavras, como bem indica o poeta Manoel de Barros, aprendendo a voar fora da asa, por meio dessa mútua relação entre ensino e aprendizagem, mediada pelas relações de carinho, respeito, luta e amizade.

\section{REFERÊNCIAS}

BENJAMIN, Walter. Magia e técnica, arte e política: ensaios sobre literatura e história da cultura. Tradução de Sérgio Paulo Rouanet. 8.ed. - São Paulo: Brasiliense, 2012.

FREIRE, Paulo. Ação Cultural para a Liberdade. Ação Cultural e Revolução Cultural. $5^{a}$ ed., Rio de Janeiro, Paz e Terra. 1981.

JOSSO, Marie-Christine. A transformação de si a partir da narração de histórias de vida. Educação. Porto Alegre/RS, ano XXX, n. 3 (63), p. 413-438, set./dez. 2007. Disponível em: http://revistaseletronicas.pucrs.br/ojs/index.php/faced/article/download/2741/2088.

LAMBERT, Maria Fátima y Monteiro, A. S. Aproximações a uma definição da educação estética e da "formação de gosto". Revista Portuguesa de Filosofia. Tomo. XLIX. Fasc. 1-2. Año 1993; página 171194.

Disponível

em:

https://www.academia.edu/1085404/Aproxima\%C3\%A7oes_a uma defini $\% \mathrm{C} 3 \% \mathrm{~A} 7 \mathrm{ao}$ da educa $\% \mathrm{C}$ 3\%A7ao est $\% \mathrm{C} 3 \% \mathrm{~A} 9$ tica e da forma $\% \mathrm{C} 3 \% \mathrm{~A} 7 \mathrm{ao}$ de gosto

LARROSA, Jorge. Experiência e Alteridade em Educação. Revista Reflexão e Ação, Santa Cruz do Sul, v.19, n2, p.04-27, jul./dez. 2011.

LEC. Projeto Político Pedagógico da Licenciatura em Educação do Campo (LEC-2010-2013/UFRRJ), 2010.

MARCUSE, Herbert. Eros e Civilização. Rio de Janeiro: Zahar Editores, 1972.

PERISSÉ, Gabriel. Estética \& Educação. Belo Horizonte: Autêntica Editora, 2009.

POLLAK, Michael. Memória, Esquecimento, Silêncio. Estudos Históricos, Rio de Janeiro, vol. 2, n.3, p. 3-15 1989. Em:http://www.uel.br/cch/cdph/arqtxt/Memoria_esquecimento_silencio.pdf

SANT'ANNA, Paulo Afranio; MARQUES, Luiz Otávio Costa. Pibid Diversidade e a Formação de Educadores do Campo. Educ. Real., Porto Alegre, v. 40, n. 3, p. 725-744, set. 2015. Disponível em $<$ http://www.scielo.br/scielo.php?script=sci_arttext\&pid=S2175-

$\underline{62362015000300725 \& \operatorname{lng}=\mathrm{pt} \& \mathrm{nrm}=\text { iso }>}$ 
SCHWARZ, Roberto. Cultura e Política. São Paulo: Editora Paz e Terra, 2009.

i A criação dos cursos de Licenciatura em Educação do Campo no Estado do Rio de Janeiro têm origem na década de 1990 com as demandas dos movimentos de luta por Reforma Agrária e por escolarização dos sujeitos da Agricultura Familiar.

i O trecho destacado é parte do Projeto Político-Pedagógico da primeira turma, aqui referenciado como LEC, 2010.

i Segundo Marcuse (1972, p. 166), Schiller indica três impulsos humanos que governam as duas dimensões antagônicas do ser (sensualidade e razão): 1. Impulso básico/sensual (passivo/receptivo); 2. Impulso formal (ativo/dominador); e o impulso lúdico que teria a função de reconciliar os primeiros impulsos, a fim de transcender a tirania da razão que empobrece e barbariza a sensualidade.

Recebido em 15 de maio de 2017 Aprovado em 15 de outubro de 2017 